\title{
Além do Estado: o surgimento da administração global ${ }^{*}$
}

\section{Beyond the State: the emergence of global administration}

\author{
Lorenzo Casini*
}

\section{RESUMO}

O artigo apresenta considerações a respeito das organizações internacionais, com foco em seus assuntos administrativos. Para tanto, é traçado um breve histórico do surgimento e dos cenários dessas organizações. As atividades e formas de organização também são questões discutidas, bem como a identificação e exposição dos tipos de administração global.

\section{PALAVRAS-CHAVE}

Organizações internacionais - atividades administrativas - administração global

* Artigo recebido em 2 de julho de 2014 e aprovado em 16 de setembro de 2014. Publicado em inglês com o título "Beyond the State: the emergence of global administration", originalmente publicado no The Global Administrative Law: The Casebook, 3. ed., 2012. Disponível em: <www. irpa.eu/wp-content/uploads/2012/08/The-Casebook-Chapter-1.pdf $>$. Acesso em: 29 set. 2014. Traduzido por Thalia Cerqueira.

** Professor associado da Universidade de Roma La Sapienza e secretário-geral do Irpa. Universidade de Roma La Sapienza, Roma, Itália. E-mail: lorenzo.casini@uniroma1.it. 


\section{ABSTRACT}

The article presents considerations about the international organizations, focusing on their administrative subjects. Therefore, it is traced a brief history of the appearance and perspectives of these organizations. The activities and forms of organization are also discussed issues as well as the identification and explanation of the types of global governance.

\section{KEYWORDS}

International organizations - administrative activities - global administration

\section{Cenário: a irrefreável ascensão das organizações internacionais}

A proliferação e diferenciação das organizações internacionais (OIs) e suas atividades têm sido consideradas verdadeiros desafios (e oportunidades) para o direito internacional desde os anos 1860, se não antes. No final do século XIX e início do século XX, muitas dessas questões eram englobadas em um "direito internacional da administração" (Martens, 1883) ou "direito administrativo internacional" (Kazanski, 1902; Reinsch, 1909; Borsi, 1912; Battini, 2003; Cossalter, 2010), e uma parte significativa das OIs existentes na época foi analisada sob o rótulo de "uniões administrativas internacionais".

A caracterização de uma instituição como uma união administrativa internacional foi originalmente concebida para enfatizar sua natureza não política (em sentido técnico/administrativo), circunscrita a funções de coordenação em assuntos administrativos. A referência aos últimos significa que as instituições em questão lidam com assuntos que são tratados pela administração em nível nacional. Outro fator diferencial é que muitas das uniões administrativas internacionais foram iniciadas por grupos privados ou agências administrativas nacionais. Por exemplo, a Organização Mundial do Turismo (OMT) foi inicialmente criada por organizações oficiais de promoção do turismo. Dada a abordagem predominante do século XIX e dos primeiros anos do século XX a respeito dos assuntos do direito internacional, ficou amplamente aceito que as uniões administrativas internacionais não deveriam ser consideradas sujeitos do direito internacional. (Wolfrum, 1995) 
Apesar disso, no entanto,

As organizações internacionais (ou OIs) - entidades intergovernamentais fundadas por tratado, em geral constituídas por secretarias permanentes, assembleias plenárias envolvendo todos os Estados membros e órgãos executivos com participação mais limitada - são um fenômeno do século XX que tem pouco em comum com as formas anteriores de cooperação institucionalizada, incluindo aquelas da antiguidade. (Alvarez, 2006:324)

Portanto, foi somente após a Segunda Guerra Mundial que as OIs começaram a crescer significativamente em número, e que o campo do direito institucional internacional (ou do direito das organizações internacionais) se desenvolveu, tipicamente voltado para as formas de cooperação que vão além do tradicional e rigoroso "direito da coexistência" (Friedmann, 1964), embora a teoria tradicional das relações internacionais sugira que as OIs e outras instituições internacionais possam ter importância mesmo sob condições realistas das relações interestatais (Klabbers, 2009).

Parece que as organizações internacionais estão se tornando cada vez mais requisitadas como objeto de estudo acadêmico, e que, junto com o estudo da organização internacional (ou governança global, para usarmos um termo mais moderno), o estudo do direito das organizações internacionais também está sendo cada vez mais reconhecido como um assunto digno de atenção. Isso se deve, em grande parte, a dois motivos. Primeiro, as regras e normas desenvolvidas por ou sob os auspícios das organizações internacionais estão cada vez mais evidentes conforme influenciam nossa vida cotidiana. Enquanto não precisamos de muito tempo para perceber o impacto que o direito da Comunidade Europeia pode exercer sobre o direito nacional, lentamente constatamos que o direito da Comunidade Europeia não é o único a afetar o direito nacional ou, em outras palavras, o nosso cotidiano. Muitos meios de subsistência poderão ser afetados pelas decisões individuais do FMI; os manifestantes contra a reunião da OMC em Seattle, ocorrida em dezembro de 1999, conseguiram perceber claramente o quão forte é a influência do direito da OMC sobre todos e cada um de nós, seja ela direta ou indireta, real ou potencial; nosso cotidiano de trabalho será influenciado, 
em maior ou menor grau, pelas atividades da OIT; e como muitos em Kosovo já descobriram, embora que pelo caminho das pedras, a Otan também pode exercer um impacto substancial na vida humana.

Isso suscita, ou deveria suscitar, perguntas óbvias acerca da abrangência exata das atividades de determinadas organizações, dos meios pelos quais elas adquirem seus poderes, da transparência de seus processos de tomada de decisão e do controle democrático e judicial sobre suas atividades. De fato, a própria legitimidade da existência e das atividades das organizações internacionais está em questão. Isso tudo se conjuga com a segunda razão pela qual o direito das organizações internacionais, como disciplina, é de interesse considerável (e cada vez mais reconhecido): a sensação de que a imagem das organizações internacionais, pelo menos entre os advogados internacionais, está passando por uma mudança, não necessariamente para melhor. Tradicionalmente, as organizações internacionais foram promovidas como os arautos da felicidade internacional, incorporando uma combinação fortuita dos nossos sonhos de "razão legislativa" e da ideia de que tudo que é internacional é maravilhoso justamente por ser internacional: estamos falando do "projeto internacional", como bem observou David Kennedy. No entanto, essa noção das organizações internacionais serem positivas por natureza parece estar se dissolvendo, em parte, sem dúvida, em decorrência da maior visibilidade do impacto do trabalho das organizações internacionais no nosso cotidiano, como também pelo fato de o Big Government estar atuando na defensiva desde os anos de Thatcher e Reagan. E se os governos representavam o Big Government, as organizações representavam estados ainda maiores. (Klabbers, 2001, 287 e ss.)

Assim, a partir da década de 1960, as OIs têm se proliferado e diferenciado e, com o fim da Guerra Fria e o surgimento da globalização, sua expansão foi ainda mais acelerada. A figura abaixo mostra claramente essa tendência. 
Figura 1

Panorama histórico do número de organizações internacionais

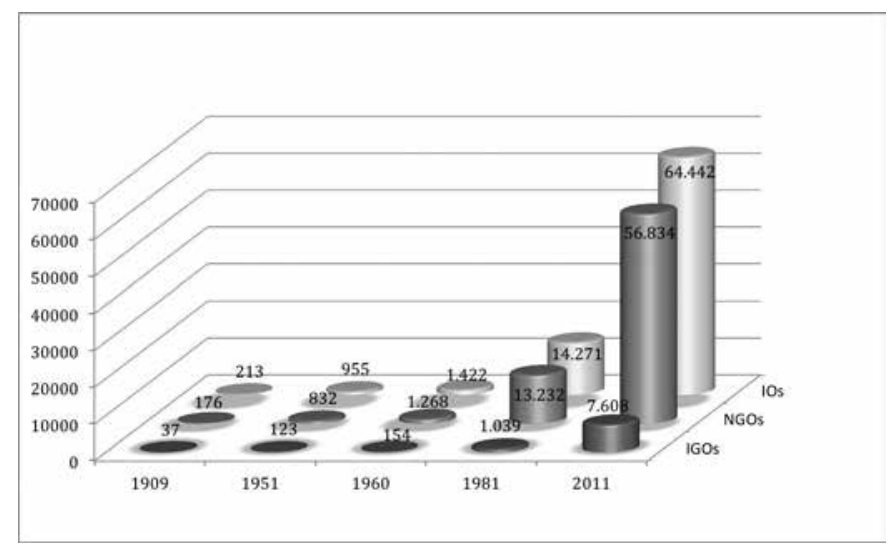

Fontes: UIA. Yearbook of international organizations. $48^{\text {th }}$ ed., Bruxelas, 2011; CASSESE, S. Relations between international organizations and national administrations. In: IISA, PROCEEDINGS, XIXTH INTERNATIONAL CONGRESS OF ADMINISTRATIVE SCIENCES (Berlin, 1983).

Em consequência desse crescimento, os juristas vêm examinando os diversos tipos de OI e propondo diferentes classificações. Inúmeras taxonomias já foram apresentadas, enfatizando a estrutura, as funções e a natureza jurídica das OIs.

A principal distinção está entre as OIs que têm Estados como seus membros (ou seja, organizações intergovernamentais (OIGs)) e aquelas que não (ou seja, organizações não governamentais (ONGs)); no entanto, com cenário composto por mais de 60 mil entidades, outros critérios de diferenciação se fazem necessários. Encontramos uma abordagem mais complexa na classificação adotada pela União das Associações Internacionais (UIA) em seu Yearbook of international organizations: são identificados 15 subtipos de OIs, incluindo federações de organizações internacionais; organizações de afiliação universal; organizações de afiliação intercontinental; organizações de afiliação regional; organizações derivadas de lugares, pessoas, produtos registrados ou outras entidades; ou organizações com formato especial, como as fundações e fundos. Cada subtipo ainda conta com especificações adicionais (ver: <www.uia.be/types-organization-type-i>).

Naturalmente, a relevância da classificação das OIs não reside apenas em seus fins estatísticos, mas também se traduz no objetivo acadêmico de "organizar o conhecimento" (Klabbers, 2009). No entanto, muitas vezes a 
diversidade de funções das OIs implica diferenças nas suas estruturas, poderes e relações com os Estados. Assim, não é de se estranhar que um dos critérios mais comuns de classificação é funcional por natureza, subdividindo-se em três subcritérios (a intensidade da cooperação que a OI busca proporcionar; a abrangência dessa cooperação; os meios utilizados para colocá-la em prática) (Virally, 1977). De acordo com esse critério, três principais distinções entre as OIs podem ser identificadas:

Em primeiro lugar, uma maior harmonia e coesão em um grupo de estados parecem proporcionar oportunidades institucionais para organizações fechadas (por exemplo, organizações regionais), que estão além do alcance das organizações com uma missão universal. Em segundo lugar, as organizações supranacionais se relacionam com diferentes autoridades e assuntos de seus Estados-membros, enquanto em outras organizações, como as intergovernamentais, apenas os governos nacionais entram em cooperação. Por fim, seu conhecimento especializado e objetivo limitado podem conferir poderes a organizações especiais ou técnicas que faltam às organizações generalistas. (Schermers e Blokker, 2011)

Dois conceitos diferentes do papel das organizações internacionais também foram discriminados: o primeiro é baseado em um entendimento progressista, funcionalista e voltado à gestão; o segundo se assemelha à noção da organização internacional como uma "ágora clássica". O primeiro conceito

pressupõe duas ideias: primeiro, que a cooperação institucionalizada entre Estados independentes contribuirá para a solução de problemas comuns, e segundo, que a maior cooperação por meio de organizações internacionais levará a um mundo melhor. Esse conceito vem das origens desse campo de estudo. Na verdade, em termos históricos, as organizações internacionais, muitas vezes, que dirá sempre, foram em sua maioria entendidas como órgãos responsáveis por uma única tarefa: gerir problemas de ordem pública. Diz a tradição que as organizações são, de fato, extensões dos Estados, e fazem o que esses Estados não conseguem realizar por conta própria. (...) Em suma, o conceito predominante na literatura sobre o tema é de uma organização internacional responsável por tarefas; um conceito de uma entidade criada 
por Estados para fazer o tipo de coisas que os Estados não conseguem fazer (ou que relutam em fazer) sozinhos, por qualquer motivo que seja: gerenciar uma hidrovia internacional, monitorar as violações dos direitos humanos, conceder empréstimos de modo a estimular o desenvolvimento econômico; facilitar relações trabalhistas pacíficas etc. Até mesmo a gestão da paz e da segurança pode, nesse sentido, ser reduzida a uma tarefa gerencial, algo que é melhor ficar a cargo de especialistas. Os estados e as organizações são extensões uns dos outros, compartilhando funções, atribuições e legitimidade, e eventualmente, acabam se tornando indistinguíveis.

(...) Há, e sempre houve, um segundo conceito de organização internacional. É o conceito da ágora clássica: uma esfera pública em que questões internacionais podem ser debatidas e, quem sabe, resolvidas. Muitos admitem, mesmo de forma implícita, que também há essa dimensão nas organizações internacionais, embora muitos tendam a desprezá-la. Isso faz com que a organização seja (não mais que) uma plataforma de discussão, onde as coisas não podem ser simplesmente resolvidas e concluídas. (...)

O conceito ágora é uma visão menos progressista, menos otimista e menos moderna sobre as organizações internacionais. Segundo esse ponto de vista, as organizações internacionais não foram criadas para resolver nenhum problema em particular, muito menos para redimir a humanidade. Ao contrário, elas foram criadas como instâncias em que os Estados podem se reunir, trocar ideias e discutir seu futuro comum, sem ter necessariamente em vista a resolução de problemas, ou podem até mesmo chegar a um desenlace, mas apenas pelo debate em si. (Klabbers, 2005)

Assim, não é de surpreender que a complexidade desse campo desse margem a novas tentativas de classificar as OIs ao retomar a noção de direito administrativo internacional (a partir da qual a ideia de direito administrativo global se desenvolveu). Por exemplo, os órgãos reguladores internacionais podem ser divididos em três tipos principais: A) organizações públicas internacionais, que incluem organismos da ONU e órgãos especializados, OIGs regionais e organizações supranacionais; B) tribunais internacionais; e C) redes transgovernamentais, como a Ocde ou o G-20 (Kinney, 2002). 
A regulamentação internacional é agora tão extensa que muitos estudiosos têm considerado que a autoridade reguladora não reside apenas, ou principalmente, nos governos nacionais ou locais; em vez disso, ela é compartilhada por uma combinação de entidades, incluindo governos, redes transgovernamentais e organizações públicas internacionais, que compõem um complexo sistema de governança internacional. (...) As organizações públicas internacionais são análogas às entidades administrativas nacionais: são órgãos reconhecidos com estruturas e responsabilidades previstas em lei, ou seja, tratados e outros acordos intergovernamentais. Em geral, são constituídas principalmente por Estados-nação, e costumam ser fundadas por tratados ou outro acordo internacional que determina sua estrutura, suas responsabilidades e poderes. As organizações públicas internacionais fazem uso de muitos procedimentos administrativos para cumprirem com suas responsabilidades.

Além disso, de modo geral, enquanto as organizações públicas internacionais participam de atividades legislativas e judicantes e as redes colaboram na elaboração de políticas, há uma variedade considerável nos processos que cada entidade usa na execução dessas funções. (Kinney, 2002:419, 422)

A ascensão das redes globais, em particular, demonstrou que a proliferação de OIs tem sido, em muitos casos, acompanhada não só pelo aumento da diferenciação na estrutura organizacional, mas também pela crescente complexidade de muitos governos. Existem diversos elementos que compõem essa complexidade: o aumento da densidade de normas e a extensão dos mandatos; as relações multifacetadas entre as próprias OIs e entre elas e outros agentes; e o simples aumento no número de Estados participantes nas OIs (a OMC, por exemplo, tem hoje mais de 150 Estados-membros; na formação original do Gatt, em 1947, havia apenas 23 países representados). Em alguns casos, as redes de OIs trabalhando em conjunto foram além da coordenação interagências e da cooperação, o que levou ao desenvolvimento de novos formatos institucionais.

Isso acontece, por exemplo, quando os Estados e as próprias OIs fundam outras entidades ou comitês especializados: tomemos, por exemplo, a Agência Internacional de Investigação do Câncer (Iarc), criada em 1965 como extensão da OMS, que possui, no entanto, seus próprios órgãos dirigen- 
tes; ou até mesmo a famosa Comissão do Codex Alimentarius. Um segundo exemplo é a criação de mecanismos ou até mesmo entidades específicas dentro das OIs para articular órgãos administrativos nacionais, como o sistema da Organização para a Cooperação Econômica e Desenvolvimento (Ocde) de Pontos de Contato Nacionais (PCN), segundo os termos das Diretrizes para Empresas Multinacionais da própria Organização. Um terceiro exemplo diz respeito à crescente prática das OIs em fechar contratos com entidades privadas ou, quando mais ambiciosas, implementar mecanismos de parcerias público-privadas (PPP).

As OIs não são simples repositórios de práticas estatais ou agentes delegados dos Estados. Suas próprias práticas têm importância e suas ações têm consequências normativas além daquelas que lhes são explicitamente atribuídas. As OIs são novos agentes legisladores em seu próprio direito e seu impacto normativo não pode ser reduzido àquele dos seus Estados membros.

Também é importante admitir que as OIs se multiplicam, proliferam, interagem e se reproduzem por diversos órgãos secundários. Às vezes, elas até têm o intuito de criar outras instituições que sejam claramente independentes delas, da mesma forma que o Conselho de Segurança quis fazer quando instituiu dois tribunais ad hoc de crimes de guerra. Em governos que lidam com o controle de armas ou direitos humanos, é necessário elaborar organogramas completos para manter o controle dos subórgãos ora encarregados com sua interpretação ou cumprimento. (Alvarez, 2007:597 e ss.)

O resultado dessa ascensão irrefreável é que hoje as atividades das OIs abrangem campos tão diversos quanto

preservação florestal, controle da pesca, regulação da água, proteção ambiental, padronização e segurança alimentar, normas contábeis e financeiras, governança da internet, regulamentação farmacêutica, proteção da propriedade intelectual, proteção de refugiados, normas de produção de café e cacau, normas trabalhistas, regulamentação antitruste, regulamentação e financiamento de obras públicas, normas do comércio, regulamentação de finanças, seguros, investimentos estrangeiros, terrorismo internacional, controle de guerra e de armas, 
navegação aérea e marítima, serviços postais, telecomunicações, energia e resíduos nucleares, lavagem de dinheiro, educação, migração, manutenção da ordem pública, esportes e saúde. (Cassese, 2012)

Isso também explica por que as OIs precisaram encontrar novas maneiras para se desenvolver.

Os Estados se desenvolvem a partir e em torno de um centro. As instituições administrativas globais se desenvolvem por meio de conexões mútuas a partir de pontos periféricos, em forma federativa ou associativa.

A maneira mais simples e mais comum pelas quais as instituições administrativas globais se desenvolvem é quando os Estados se associam para instituir um órgão sobre-estatal; como quando as organizações internacionais da ONU nascem de acordos entre Estados, mas também promovem outros acordos. Por exemplo, a Organização Marítima Internacional (OMI) promoveu acordos nas áreas de segurança, proteção do ambiente marinho e de transporte marítimo de materiais nucleares. Além dos Estados, os órgãos subestatais também podem aderir para instituir organismos internacionais. Os órgãos nacionais de regulamentação dos mercados financeiros estão associados na Iosco; já os órgãos nacionais de regulamentação de seguros se reúnem no Iais; a Rede Internacional da Concorrência (ICN) reúne autoridades nacionais da concorrência; o Instituto de Estabilidade Financeira (FSI), fomentado pelos ministérios da fazenda e bancos centrais dos países do G7, reúne ministros da fazenda e os diretores desses bancos.

Um terceiro tipo de organização global é composta nem por Estados, nem por entidades subestatais de nível inferior, mas por outras organizações globais, que atuam isoladamente ou em conjunto. Por exemplo, a Comissão de Medidas Fitossanitárias (CMF) foi instituída pela FAO, e o Centro Internacional para Arbitragem de Disputas sobre Investimentos (Ciadi) foi criado pelo Banco Mundial. Em outros casos, diferentes organizações globais se reúnem para fundar uma outra organização global. O Instituto de Estabilidade Financeira (FSI) foi criado em 1999 pelo Banco de Compensações Internacionais e o Comitê da Basileia de Supervisão Bancária. A Comissão do Codex Alimentarius foi criada pela FAO e pela Organização Mundial da Saúde (OMS). 
A Organização Mundial do Comércio (OMC) e a Conferência das Nações Unidas sobre Comércio e Desenvolvimento (Unctad) juntas fundaram o Centro de Comércio Internacional. (Cassese, 2005:674-675)

\section{As atividades das organizações internacionais como forma de administração}

Ao abordar as OIs e suas funções, no cômputo geral, o direito institucional internacional talvez não tenha sido eficaz em apresentar uma estrutura aprofundada das atividades operacionais ou de natureza administrativa das OIs (embora haja algumas exceções). Os trabalhos acadêmicos sobre direito institucional internacional muito têm contribuído ao tratar de questões constitucionais relativas às competências das OIs e seus diversos organismos, das relações entre as OIs e seus Estados-membros (Sarooshi, 2005; Alvarez, 2006), bem como das questões envolvendo seus funcionários. As dificuldades jurídicas relacionadas ao processo de tomada de decisão interno às OIs (Cox e Jacobson, 1973; Von Bernstorff, 2008; Schermers e Blokker, 2011) e os assuntos intraorganizacionais, como o relacionamento entre as sedes das OIs e suas sucursais, são temas menos visitados. De certa forma, essa tendência acompanha um fenômeno semelhante vivenciado pelo direito administrativo nacional durante o século XX: por um longo tempo, os administrativistas voltavam-se principalmente para as ações - e para a avaliação das ações dos organismos públicos, sem considerar sua estrutura organizacional interna e as maneiras pelas quais operavam. No entanto, desde os anos 1950, uma maior atenção tem sido dada aos processos administrativos e às transformações institucionais (Cassese, 2000).

Com isso, há tempos se reconhece que as percepções do direito administrativo e do direito público, em termos mais gerais, são capazes de proporcionar alguns recursos conceituais para melhor enquadrar o direito e a prática das organizações internacionais. Não é de se estranhar que determinadas características formais e operacionais das OIs possam se parecer com aquelas encontradas nas administrações nacionais. As abordagens funcionalistas mencionadas anteriormente, por exemplo, se sobrepõem às teorias de direito nacional na medida em que a função pública da ação administrativa (o interesse público, identificado e regulamentado por lei) justifica a aplicação de regras do direito administrativo voltadas ao público para dirigir os agentes administrativos (Virally, 1974). Dessa forma, é possível identificar certas 
atividades como "administrativas" em termos teóricos (conhecido como o Begriff der Verwaltung alemão), mas a tentativa de se chegar a uma única definição continua a ser difícil e desnecessária em termos práticos. Entender a administração com um foco funcional orientado a alcançar um objetivo público empresta variabilidade à delimitação da esfera pública: não há, portanto, uma definição única, mas sim uma série de noções sobre o que pode constituir a "administração pública".

Em termos mais gerais, a prática das OIs também traça um paralelo com a experiência nacional anterior com certas questões, como a proliferação e fragmentação dos órgãos públicos; a crescente utilização de instrumentos de direito privado; o aumento da regulação (rulemaking) administrativa (uma das principais características do New Deal norte-americano, contemplada no Administrative Procedures Act, de 1946); e a criação de diversas sucursais (uma característica típica do sistema administrativo francês). Entretanto, qualquer transposição pura e simples dos sistemas jurídicos estatais para as práticas complexas das instituições intergovernamentais na governança global é questionada por existirem diferenças fundamentais entre essas iniciativas (Sarooshi, 2008; Kingsbury e Casini, 2009; von Bogdandy et al., 2010): “o pleno desenvolvimento do direito internacional como direito internacional público parece pouco factível sem que ele se alicerce em doutrinas e conhecimentos jurídicos administrativos nacionais elaborados no século passado"; mas é claro que "isso não defende a elaboração de 'analogias nacionais' simplistas: as diferenças entre as instituições nacionais e as instituições internacionais são extremamente importantes" (von Bogdandy et al., 2010:24).

Além disso, o fato de que muitas atividades relevantes das OIs podem ser consideradas de natureza administrativa não sugere a existência de uma administração pública global geral; não há governo global ou parlamento global, nem existem equivalentes globais reais das demais estruturas dentro das quais as administrações nacionais são compreendidas. No entanto, algumas exigências normativas e princípios processuais são bastante comuns em diversas OIs para considerar que um campo unificado seja possível de ser distinguido: a transparência no rulemaking; o due process (em certos casos, incluindo mecanismos de notice-and-comment, audiências e reason-giving) nas decisões que afetam diretamente as entidades privadas; mecanismos de avaliação para corrigir erros e garantir a racionalidade e a legalidade; e, além dos mecanismos de revisão, uma variedade de outros dispositivos para promover accountability. Esses elementos estão entre os principais conjuntos de 
questões na exploração do campo unificado do estudo e da prática jurídica ora denominado direito administrativo global (GAL, do inglês global administrative law).

A prática contemporânea de muitas OIs, de fato,

pode ser entendida e analisada como ações administrativas: rulemaking (elaboração de normas), adjudication (julgamentos administrativos) de interesses concorrentes, além de outras formas de gestão e de decisão regulatória e administrativa. $\mathrm{O}$ direito nacional pressupõe uma percepção comum sobre o que é a ação administrativa, mesmo que ela possa ser definida de forma negativa - como atos estatais que não são nem legislativos, nem judiciais - e mesmo que a linha divisória entre essas categorias seja tênue. Além do domínio do Estado, esse tipo de diferenciação funcional fixa não se sustenta; o cenário institucional é muito mais diversificado que o nacional. No entanto, muitas das instituições internacionais e governos que se dedicam à "governança global" realizam funções que a maioria dos advogados públicos nacionais chamaria de tipicamente administrativas: elas operam abaixo do nível das conferências diplomáticas e dos tratados de grande repercussão, mas no geral regulam e administram vastos setores da vida socioeconômica por meio de decisões específicas e rulemaking. Em termos conceituais, acreditamos que a ação administrativa pode ser diferenciada da legislação pelos tratados, e do julgamento (adjudication) pela resolução ocasional de litígios entre Estados ou outras partes litigantes. Assim como no cenário nacional, a ação administrativa em nível global tem elementos legislativos e adjudicatórios. Ela compreende o rulemaking, não na forma de tratados negociados pelos Estados, mas de normas e regras de aplicação geral adotadas por órgãos subsidiários. Ela também inclui decisões informais tomadas para supervisionar e implementar regimes regulatórios internacionais. Para fins de definição provisória, a ação administrativa global compreende rulemaking, adjudications e outras decisões que não constituem nem a celebração de tratados, nem a simples resolução de litígios. (Kingsbury, Krisch e Stewart, 2005:17)

Muitos princípios do direito administrativo são ativamente adotados em determinadas OIs, dando base para uma discussão séria e crítica no trabalho de outras instituições. No entanto, algumas das exigências feitas por referência 
aos princípios do direito administrativo não são realistas, além de potencialmente contraprodutivas. Por exemplo, o excesso de accountability às pessoas erradas pode ser patológico; problemas gigantescos, e talvez insuperáveis, surgem na tentativa de garantir a participação direta dos atores da sociedade civil e a representação adequada de seus interesses, o que pode, muitas vezes, levar a acordos inevitáveis (em nível global, os direitos de participação devem ser acordados tendo em vista a natureza dos diferentes atores envolvidos, que pode ser tanto pública quanto privada - como os Estados e as administrações nacionais - ou ambos); as exigências de notice-and-comment para o rulemaking podem facilitar que o processo seja dominado por grupos com interesses específicos; e o direito a uma audiência demorada e a recurso poderá "engessar" os procedimentos e dissuadir uma agência subfinanciada e sobrecarregada até mesmo de agir (Kingsbury e Casini, 2009).

As instituições internacionais constituem outro campo para a evolução do direito administrativo. Nos últimos anos, cada vez mais o arbítrio legislativo tem sido delegado não aos agentes nacionais, mas às instituições internacionais - tanto regionais quanto globais. Muitas vezes, os mesmos grupos nacionais que influenciam os legisladores a delegar autoridade ao executivo nacional usam sua influência para induzir seus governos a se juntarem a uma instituição internacional que goza de poder de decisão perante seus Estados-membros. No entanto, uma vez que tais instituições não têm a divisão paradigmática de poderes que caracteriza as democracias - Legislativo, Executivo e Judiciário - , as características do direito administrativo internacional diferem do direito administrativo nacional. Como resultado, certos princípios do direito administrativo e constitucional nacional não necessariamente se aplicarão aos organismos internacionais. Por exemplo, a exigência de que os tribunais sejam instituídos por legislação primária, encontrada em muitas constituições nacionais e que reflete garantias democráticas importantes proporcionadas pelo processo legislativo, muitas vezes é irrelevante no contexto de um organismo internacional, cuja constituição e procedimentos dependem menos de um órgão legislativo. No entanto, conforme os tratados atribuem responsabilidades e poderes de tomada de decisão aos órgãos de tratados, surgirão questões de direito administrativo internacional semelhantes às questões de direito administrativo nacional. Como no direito administrativo nacional, o direito administrativo de uma instituição 
internacional derivará de decretos dos partidos dos Estados (no tratado que funda a instituição), pautado nas diversas contribuições de seus órgãos executivos e nas decisões dos seus órgãos adjudicantes. As tensões dos principais agentes que existem entre o Legislativo e o Executivo na esfera nacional também são encontradas em nível internacional entre os partidos dos Estados e os diferentes órgãos de tratados, e entre as partes de cada órgão de tratado. Logo, assim como acontece no direito administrativo nacional, que reflete o equilíbrio político interno do poder, o direito que restringe a liberdade de ação dos diversos atores da instituição internacional refletirá o equilíbrio específico dos poderes entre os partidos do Estado e o equilíbrio de poder dentro de cada instituição internacional. (Benvenisti, 2005:320-321)

A crescente diversidade e abrangência das atividades das OIs deu margem à emergência de uma série de questões jurídicas e implicações que podem ser proveitosamente abordadas por meio de uma estrutura do direito administrativo. O desenvolvimento de funções e capacidades suscita pressões normativas específicas relativas à informação (exigências de transparência ativa e acesso à informação, como também exigências de confidencialidade e privacidade, e para controles jurídicos ou políticos, exigências sobre a coleta e uso de informações para elaboração de políticas), além de pressões mais gerais pela avaliação das ações de ordem administrativa, e por uma accountability mais intensa, com consequências para os regimes de responsabilidade e impunidade. Além disso, a proliferação deOIs e outras instituições que exercem poder ou autoridade pública na governança global, somada às diversas formas de diferenciação institucional e descentralização, e às operações de campo complexas, tem intensificado a necessidade por princípios que estruturem as relações entre esses diferentes atores. Esses princípios podem ser considerados de ordem constitucional ou princípios gerais de direito público; de forma mais pragmática, eles podem ser entendidos como elementos de coordenação, mas em muitos casos se configuram como princípios de administração. Essa perspectiva administrativa tem a vantagem adicional de permitir a análise de práticas que já ocorrem nas OIs (e que são abordadas de forma insuficiente na erudição do direito internacional), que refletem as mudanças nos padrões das práticas de gestão e filosofias contemporâneas de forma mais geral, como as práticas da nova gestão pública (steering-not-rowing, encargos de usuário, separação entre financiadores e prestadores de serviços) ou a terceirização e governança por contrato: 
[O] grande número de normas, a elaboração de regras e princípios e surgimento dos tribunais ratificam o alto grau de institucionalização (ou legalização, como os estudiosos norte-americanos gostam de dizer) do sistema administrativo global. Isso está diretamente relacionado com a maior eficácia das decisões globais direcionadas aos cidadãos nacionais, organizações e corporações. Quanto mais as organizações globais ampliam seu campo de atuação para além dos Estados e organizações públicas nacionais, mais importante é garantir o respeito pelo Estado de Direito, pelo princípio da participação, bem como pelo dever de apresentar decisões fundamentadas. Esses procedimentos são cruciais para garantir a proteção dos cidadãos, organizações e corporações, não apenas em seu relacionamento com os Estados e outros poderes públicos nacionais, mas também nas suas relações com os novos poderes públicos globais. (Cassese, 2005:694)

Nesse contexto, os mecanismos tradicionais pautados no consentimento do Estado, expresso em tratados ou no costume, simplesmente não são mais capazes de dar conta de todas as atividades globais. Um novo espaço de regulamentação está emergindo, distinto daquele das relações interestatais, transcendendo a esfera de influência tanto do direito internacional quanto do direito administrativo nacional: é o "espaço administrativo global". As OIs tornaram-se muito mais do que instrumentos dos governos de seus Estadosmembros. Em vez disso, elas estipularam suas próprias normas e regulam seu próprio campo de atuação; elas criaram e seguem seus próprios procedimentos legais; e ainda podem conceder direitos de participação para os atores, quer públicos ou privados, contemplados por suas atividades. Por fim, as OIs surgiram como verdadeiras administrações públicas globais.

Dessa forma, a administração global

tem uma importância crescente tanto como resultado quanto como recurso de estruturação da ordem global. A administração global é capaz de impactar de forma substancial as pessoas e seus direitos, as possibilidades de democracia ou autonomia nacional ou local, bem como outros valores profundamente internalizados. Compreender os processos e trajetórias da administração global é de uma importância prática e normativa sem precedentes. Para tanto, é preciso contestar o volume massivo, a policentricidade e obscuridade das interações que 
constituem essa administração. Os padrões de poder e autoridade na administração global são muito menos estruturados do que aqueles que sustentam partes essenciais dos sistemas administrativos nacionais. A diferenciação institucional é menos completa, as funções não estão claramente atribuídas, as hierarquias não são muito discriminadas e não há uma distinção clara entre as esferas da administração e da legislação, ou entre os princípios administrativos e constitucionais e as autoridades avaliadoras. (Kingsbury e Donaldson, 2011)

Um dos principais elementos que identifica a natureza administrativa da organização e as atividades dessas instituições reguladoras globais é a ausência de qualquer esforço para torná-la legislativa ou judicial em essência (dentro das estruturas tradicionais conceituais do direito internacional). Isso por si só gera problemas específicos em termos de legitimidade e accountability. Em outras palavras, as estruturas, procedimentos e padrões normativos para a tomada de decisão regulamentar aplicáveis às instituições globais (incluindo transparência, participação e avaliação), junto com os mecanismos pautados em regras para a aplicação dessas normas, estão começando a formar um campo específico da teoria e da prática jurídica: o campo do direito administrativo global.

\section{Tipos de administração global}

Uma vez que se admite que as atividades das OIs podem ser vistas como uma forma de administração, conseguimos identificar diferentes tipos de instituições globais.

Um primeiro tipo inclui a administração global feita por organizações intergovernamentais formais. Esse é o modelo tradicionalmente adotado pelos Estados na criação de instituições internacionais. Temos como exemplos as Nações Unidas, a OMS, a OIT, a Unicef ou a Organização Mundial da Propriedade Intelectual (Ompi). Embora a concepção institucional de tais OIs tenha sido estudada por muitas décadas, os tipos de atividades que se tornaram corriqueiras para esses órgãos nos últimos anos apresentam características semelhantes à ação administrativa. Tomemos, por exemplo, as várias formas de recomendações, diretrizes, melhores práticas, recomendações técnicas, resultados, conclusões, regras de comitê e outros produtos normativos produzidos pelas OIs: eles desencadearam uma crescente demanda 
por transparência, justificação (reason-giving), avaliação e, em alguns casos, participação ou accountability perante esses instrumentos; várias agências têm abordagens muito diferentes para essas demandas e, muitas vezes, há incerteza sobre qual é o enquadramento jurídico exato aplicável a esse tipo de atividades, e sobre quais normas processuais são - ou deveriam ser - necessárias. Outros exemplos incluem as ações emergenciais das OIs, como aquela realizada pela OMS em relação à crise da Sars, e as operações de campo de inúmeros organismos mundiais, sejam conduzidas por sucursais permanentes, pelo envio de equipes visitantes provenientes da sede ou pela contratação de outras entidades públicas ou privadas para a prestação de serviços.

Um segundo tipo de administração global diz respeito às organizações público-privadas híbridas e aos organismos privados que exercem funções públicas. Tanto os Estados quanto as OIs formam e conduzem cada vez mais parcerias com entidades comerciais privadas e entidades da sociedade civil (Bull e Mc Neill, 2007). Por exemplo, o Fundo Global tem laços estreitos com a Organização Mundial da Saúde, mas é, em termos jurídicos formais, uma fundação suíça. Seu Conselho Diretor é composto por doadores, Estados beneficiários e representantes de grupos afetados pelo HIV e outras doenças infecciosas combatidas pelo Fundo Global; ele tem um sofisticado sistema de avaliação independente e está vinculado a algumas das grandes fontes de financiamento, como a Fundação Gates. Outros exemplos são a Corporação da Internet para Atribuição de Nomes e Números (Icann), a Agência Mundial Antidoping (Wada), os Conselhos de Manejo privados para produtos florestais e marinhos (compostos por membros da indústria e da sociedade civil) e a Organização Internacional para Padronização (ISO). Portanto, esse tipo de administração global abarca tanto as organizações público-privadas híbridas quanto os organismos privados que exercem funções públicas. Essas instituições podem ser definidas de forma depreciativa como organizações intergovernamentais não formais. Buscando um entendimento mais positivo dessas entidades, elas representam um exemplo muito interessante de como o uso dos instrumentos do direito privado para realizar funções públicas é comum também em nível internacional.

Um terceiro tipo de administração global são as redes transgovernamentais e transnacionais. Elas têm formatos menos estruturados de governança, onde as relações entre os Estados, OIs e/ou outros atores são menos formais, embora possam ser ainda mais eficazes do que no contexto das OIGs tradicionais. Exemplos desse tipo de rede são o G-8 e o Comitê da Basileia: As "redes transgovernamentais" podem ser definidas como "todas as diferentes 
maneiras que instituições governamentais distintas usam para interagir com seus pares internacionais ou superiores, em paralelo a interações interestatais mais tradicionais". Portanto, uma rede é "um padrão de relações regulares e intencionais entre unidades governamentais semelhantes que trabalham para além das fronteiras que separam os países uns dos outros e que demarcam a esfera 'nacional' da esfera 'internacional'” (Slaughter, 2004:14 e ss.).

Em particular,

três fatores principais - inovação tecnológica, expansão da regulamentação nacional e surgimento da globalização - têm promovido o desenvolvimento das redes. Entretanto, esses fatores datam de muito tempo atrás. Na verdade, os debates sobre transnacionalismo/“soberania ameaçada" da década de 1970 previram boa parte da atual discussão sobre redes. Entretanto, cada um desses fatores parece estar se intensificando no século XXI, incentivando cada vez mais os reguladores a cooperarem com seus pares.

Assim como a própria globalização, o desenvolvimento de redes não é distribuído uniformemente, seja em termos geográficos ou por área-problema. As redes são mais evidentes entre os funcionários de órgãos reguladores, embora também possam ser encontradas entre juízes e legisladores. As redes se concentram entre os estados mais ricos e industrializados que possuem condições administrativas menos complexas. O desenvolvimento das redes pelas áreas da política é particularmente diversificado devido a diferentes imperativos funcionais. (Raustiala, 2002:16)

Outros exemplos são as redes público-privadas, cujos atores envolvidos também incluem entidades privadas, como a Conferência Internacional de Harmonização (ICH). Portanto, o termo "redes" aqui indica tanto as redes completamente públicas - ou transgovernamentais - quanto as redes público-privadas híbridas.

O quarto - e último - tipo de administração global ultrapassa os conceitos de instituição e de redes e inclui formas mais complexas de governança, tais como sistemas regulatórios globais informais, híbridos ou multiníveis. Tais casos são caracterizados por mecanismos e procedimentos compostos envolvendo vários atores em nível internacional e nacional. Como exemplos, temos os processos globais e nacionais no âmbito do Tratado de Cooperação em 
Matéria de Patentes; o reconhecimento mútuo no campo da livre circulação de profissionais; os procedimentos de tomada de decisão na governança de pescas e silvicultura; a Convenção do Patrimônio Mundial; e o mecanismo de desenvolvimento limpo e o comércio de emissões. Esse é o tipo mais sofisticado de administração global: o exercício das funções públicas é assegurado pela criação de um conjunto de princípios, regras e instituições que atuam tanto em nível nacional quanto internacional.

Essa taxonomia não tem a pretensão de oferecer uma única possibilidade de entendimento. Ao contrário, ela pode ser integrada e comparada de forma proveitosa com outras classificações, como aquela que se baseia em

[c]inco tipos principais de regulação administrativa globalizada (...): administração por organizações internacionais formais; administrações com base em ação coletiva por parte de redes transnacionais de funcionários do governo; administração distribuída conduzida pelos reguladores nacionais sob regimes de tratado, acordos de reconhecimento mútuo ou normas de cooperação; administração por acordos intergovernamentais-privados híbridos; e administração por instituições privadas com funções reguladoras. (Kingsbury, Krisch e Stewart, 2005; Kingsbury e Donaldson, 2011)

Ao comparar essas taxonomias, a categoria "administração distribuída" discriminada logo acima ficaria classificada no grupo de formas complexas de governança da primeira taxonomia apresentada. Outras complexificações podem surgir uma vez que as categorias de acordos intergovernamentais-privados híbridos e as instituições privadas podem se mesclar, e as redes transgovernamentais podem ser tratadas em conjunto com as redes público-privadas híbridas. Hoje a divisão público-privada é turva, e é difícil encontrar redes ou sistemas que não tenham nenhum grau de hibridização: na área do financiamento privado, por exemplo, existem diversos órgãos estatais e da UE que interagem com bancos, seguradoras e bolsas de valores. Na verdade, muitas vezes as interações estruturadas entre autoridades públicas e agentes privados representam uma característica fundamental das "redes de harmonização", ou seja, "redes de autoridades públicas reguladoras (por vezes em colaboração com parceiros privados) que investem na harmonização de suas regras nacionais, estipulando normas e outras regras" (Wessel e Berman apud Pauwelyn, Wessel e Wouters, 2012). 
Por fim, esses quatro tipos podem sobrepor-se e, muitas vezes, combinarse entre si: uma OIG pode ser parte de uma forma complexa de governança e/ou de uma rede; uma instituição público-privada pode atuar como um jogador-chave em uma rede transnacional. Além disso, as fronteiras entre essas categorias (como acontece com a maioria, se não todas, dessas classificações de OIs) "são tão tênues" porque "sua prática é mais heterogênea do que essas distinções podem sugerir" (Schermers e Blokker, 2011). No entanto, a taxonomia descrita no início dessa seção proporciona um substrato propício para a distinção das quatro formas diferentes de administração atualmente vigentes na arena global: "enquanto for claro que a classificação tem a simples função de organizar o conhecimento, nada mais que isso", ela poderá ser um exercício útil, mas "é importante reconhecer que, para o advogado, cada organização internacional é única, alicerçada em seus atos constitutivos e influenciada pelos rumos que seu desenvolvimento tomará com base em configurações políticas específicas" (Klabbers, 2009).

Fica claro, portanto, que a diferenciação institucional é uma característica importante das OIs contemporâneas e da governança global contemporânea sobre uma ampla gama de questões mais gerais. Esse fenômeno tem uma dimensão horizontal - (relativa às relações entre as OIs e outros atores globais) - e outra vertical (as relações entre as OIs, os Estados e as administrações nacionais). Hoje a maioria das OIs pode ser estudada segundo essas coordenadas: na OMC, por exemplo, encontramos tanto a dimensão vertical das relações entre a OMC e as administrações nacionais de seus membros, quanto a dimensão horizontal, manifestada no reconhecimento, por parte da OMC, das normas regulatórias definidas por outros órgãos reguladores globais (sob os termos dos acordos TBT e SPS). Ademais, a proliferação e diferenciação das OIs levam, por um lado, à multiplicação de sucursais da OI e, por outro, a novos organismos nacionais especializados (isso geralmente acontece em sistemas público-privados híbridos, como a ISO, e governanças da internet e esportes).

No entanto, do ponto de vista organizacional, é possível identificar algumas características básicas comuns a todas essas diferentes instituições.

A estrutura organizacional das organizações globais geralmente pode ser dividida em quatro partes: um colegiado geral, denominado assembleia, em que todos os estados participantes, outras organizações nacionais e organizações internacionais estão presentes; um colegiado mais restrito, normalmente chamado de conselho, cujos membros são eleitos 
pela assembleia; um órgão executivo, chamado secretariado, formado por funcionários regulares da organização; e os comitês, que costumam ser formados por funcionários das administrações nacionais.

As estruturas variam de uma organização para outra. Há algumas, por exemplo, que não têm o seu próprio secretariado. O Comitê da Basileia de Supervisão Bancária foi instituído pelo Banco de Compensações Internacionais, e o comitê do Clube de Paris (1956) é apoiado pelo Ministério da Fazenda francês. Outras organizações globais têm aparelhos regionais adicionais ou descentralizados. Outras, ainda, são constituídas sob a forma de um "grupo", como é o caso do Grupo Banco Mundial, formado por cinco instituições diferentes - o Banco Internacional para Reconstrução e Desenvolvimento (Bird), a Associação Internacional de Desenvolvimento (IDA), a Corporação Financeira Internacional (IFC), a Agência Multilateral de Garantia de Investimentos (Miga) e o Centro Internacional para Arbitragem de Disputas sobre Investimentos (Ciadi).

Embora os Estados tenham uma divisão estável de poderes entre os diferentes órgãos, as instituições globais têm, no máximo, uma divisão de funções entre os diferentes órgãos.

E há até mesmo organismos que são constituídos pelos mesmos participantes, mas têm diferentes funções e executam tarefas diferentes. Na OMC, esse é o caso do Conselho Geral, do Órgão de Solução de Controvérsias e do Órgão de Exame das Políticas Comerciais.

Igualmente indistintas são as linhas que distinguem os participantes dos não participantes e os Estados das organizações privadas (organizações governamentais e não governamentais, para usar a terminologia padrão). Na Organização Internacional de Defesa Civil (Icdo) participam ambos filiados e membros associados sem direito a voto. No Iais, os observadores, como as seguradoras e suas associações, profissionais e consultores também participam. Existem muitas organizações governamentais que aceitam organizações não governamentais como seus membros: a UPU, UIT, OMM, OIT, Ompi e a Organização Internacional de Aviação Civil (Icao). Na Icao, por exemplo, participam a Associação Internacional de Transporte Aéreo, o Conselho Internacional dos Aeroportos, a Federação Internacional das Associações de Pilotos de Aeronaves, o Conselho Internacional de Proprietários de Aeronaves e Associações de Pilotos. Por fim, muitas organizações globais aceitam 
uniões de Estados (principalmente a União Europeia) como membro. A $\mathrm{OMC}$, Icdo e o Conselho Oleícola Internacional seguem esse princípio. Conforme nos distanciamos do Estado, a linha entre o público e o privado se torna cada vez mais indistinta. Do ponto de vista organizacional, a ordem jurídica global não segue um único modelo. Ao contrário, ela é um exemplo de "adhocracia", no sentido de que se adapta às funções que devem ser desempenhadas, setor por setor. Funções, organizações, o equilíbrio interno dos poderes e as relações entre público e privado, todas variam de acordo com necessidades específicas. (Cassese, 2005:678 e ss.)

Por último, o escopo e a diferenciação das OIs e suas atividades são acompanhados por uma multiplicidade de regras, princípios, decisões, soft law e normas não jurídicas. Em alguns casos, essa disseminação de funções normativas levou à criação de ordenamentos jurídicos setoriais complexos, que muitas vezes exibem características singulares. Tomemos, por exemplo, o caso da "ordem mundial" no setor da saúde pública: por um lado, embora a OMS tenha sido criada em 1948 como uma organização normativa com poderes para adotar convenções e instituir regulamentos vinculativos (arts. 19 e 21 da Constituição da OMS), ela se envolveu menos que outras agências em funções claras de elaboração de leis. Por outro lado, o direito da saúde pública global inevitavelmente compreende normas produzidas em diversos setores funcionais, como segurança alimentar, controle de armas, ambiente, comércio e direitos humanos, e muitos desses setores contam com estruturas institucionais bem afastadas da OMS e que são dedicadas à elaboração de normas. $\mathrm{O}$ fato é que as atividades das OIs, e de outros atores em sistemas de governança complexos, como aqueles dos órgãos públicos nacionais, devem ser gerenciadas não simplesmente por normas formais, mas por um processo dinâmico de regulação. $\mathrm{O}$ direito do tratado (como a legislação em nível nacional) é insuficiente. A abordagem regulatória se concentra no processo, na direção da mudança, na melhoria gradual, em vez de buscar resultados imediatos, e é, por natureza, mais dinâmica do que estática. O direito não ocupa toda esfera desses processos regulatórios; e é gerado através do acréscimo, da acumulação e da mudança, pelo diálogo entre os vários sistemas existentes (Cassese, 2010).

Elementos importantes do direito administrativo são cruciais para a estruturação de todos esses processos: transparência, participação, due process, reason-giving, avaliação, accountability. 


\section{Referências}

ALVAREZ, J. E. Governing the world: international organizations as lawmakers. 31 Suffolk Transnat'l L. Rev. 596, 2007-2008.

. International organizations: then and now. 100 American Journal of International Law 324, 2006.

. International organizations as law-makers. Oxford, 2005.

AMERASINGHE, C.F. Principles of the institutional law of international organizations. Cambridge, $2^{\text {nd }}$ ed., 2005.

AUBY, J.-B. La globalisation, le droit et l'État. Paris, $2^{\text {nd }}$ ed., 2010.

BARNETT, M.; FINNEMORE, M. Rules for the world: international organizations in global politics. Cornell University Press: Ithaca, 2004.

BATTINI, S. Amministrazioni senza stato. Profili di diritto internazionale. Milão: Giuffrè, 2003.

VON BERNSTORFF, J. Procedures of decision-making and the role of law in international organizations. 9 German Law Journal 1939, 2008.

VON BOGDANDY, A. et al. (Ed.). The exercise of public authority by international institutions. Advancing international institutional law. Heidelberg, 2010.

BOISSON DE CHAZOURNES, L.; CASINI, L.; KINGSBURY, B. (Ed.). Symposium on Global Administrative Law in the Operations of International Organizations, 6:2 International Organizations L. Rev., 2009.

BORSI, U. Carattere ed oggetto del diritto amministrativo Internazionale. Riv. Dir. Int. 384, 1912.

BULL, B.; MC NEILL, D. Development issues in global governance. Public-private partnerships and market multilateralism. Abingdon, 2007.

CASINI, L. Diritto amministrativo globale. In: CASSESE, S. (Ed.). Dizionario di diritto pubblico. Milão, 2006.

CASSESE, S. Administrative law without the State? The challenge of global regulation. 37 New York University Journal of International Law and Politics 663, 2005.

. Is there a global administrative law?. In: BOGDANDY, A. et al., 2010. 
. La construction du droit administratif France et Royaume-Uni. Paris, 2000.

- Relations between international organizations and national administrations. In: IISA, PROCEEDINGS, XIXTH INTERNATIONAL CONGRESS OF ADMINISTRATIVE SCIENCES, 1983, Berlim.

. The globalization of law. 37 New York University Journal of International Law and Politics 973, 2005.

. The global polity. Global dimensions of democracy and the rule of law. Sevilha: Editorial Derecho Global; Global Law Press, 2012.

CHESTERMAN, S. Globalization rules: accountability, power, and the prospects for global administrative law. 14 Global Governance 39, 2008.

COSSALTER, P. Preface. In: CASSESE, S. Au-delà de l'État. Bruylant, 2010.

COX, R. W.; JAKOBSON, H. K. (Ed.). The anatomy of influence. Decision making in international organizations. New Haven, 1973.

ESTY, D. C. Good governance at the supranational scale: globalizing administrative law. 115 Yale Law Journal 1490, 2006.

FRIEDMANN, W. The changing structure of international law. Nova York, 1964.

HALL, R. B.; BIERSTEKER, T. J. (Ed.). The emergence of private authority in global governance. Cambridge, 2002.

KAZANSKY, P. Théorie de l'administration international. 9 Revue Générale de Droit International Public 353, 1902.

KENNEDY, D. Three globalizations of law and legal thought: 1850-2000. In: TRUBEK, D. M.; SANTOS, A. (Ed.). The new and economic development: a critical appraisal. Cambridge, 2006.

KINGSBURY, B. The administrative law frontier in global governance. 99 ASIL Proceedings 143, 2005.

; CASINI, L. Global administrative law dimensions of international organizations law. 6 (2) International Organizations 319, 2009.

;DONALDSON, M. Global administrative law. In:Max Planck Encyclopedia of International Law. Oxford, 2011.

; KRISCH, N.; STEWART, R. B. The emergence of global administrative law. 68 Law and Contemporary Problems 15, 2005. 
KINNEY, E. The emerging field of international administrative law: its contents and potential. 54 Administrative Law Review 415, 2002.

KLABBERS, J. An introduction to international institutional law. 2 ed. Cambridge: Cambridge University Press, 2009.

. The life and times of the law of international organizations. 70 Nordicj Int'l L. 287, 2001.

. Two concepts of international organizations. 2 International Organizations Law Review 277, 2005.

(Ed.). International organizations. Aldershot: Ashgate, 2005.

; WALLENDHAL, A. (Ed.). Research handbook on the law of international organisations. Cheltenham: Edward Elgar, 2011.

KOREMENOS, B. et al. The rational design of international institutions. 55 International Organization 761, 2001.

MARTENSA, F. F. Le droit international actuel des peuples civilisés. 1883.

MÖLLERS, C. et al. (Ed.). Internationales Verwaltungsrecht. Tubingen: Mohr Siebeck, 2007.

NEUMEYER, K. Internationales Verwaltungsrecht, Verlag für Recht und Gesellschaft, Munich, Zurich, v. 1, 1910, v. 2, 1922, v. 3 I, 1936, v. 3 II, 1930, v. $4,1936$.

PAUWELING, J.; WESSEL, R.; WOUTERS, J. (Ed.). Informal international lawmaking: mapping the action and testing concepts of accountability and effectiveness. Oxford, 2012.

RAUSTIALA, K. The architecture of international cooperation: transgovernmental networks and the future of international law. $43 \mathrm{Va}$. J. Int'l L. 16, 2002-2003.

REINSCH, P. International administrative law and national sovereignty. 3 AJIL 1, 1909.

RILES, A. The anti-network: private global governance, legal knowledge, and the legitimacy of the State. 56 Am. J. Comp. L. 605, 2008.

SANDS, P.; Klein, P. Bowett's law of international institutions. $5^{\text {th }}$ ed. Londres, 2001.

SAROOSHI, D. International organizations and their exercise of sovereign powers. Oxford, 2005. 
.The role of domestic public law analogies in the law of international organizations. 5 International Organizations 237, 2008.

SCHEPEL, H. The Constitution of private governance. Product standards in the regulation of integrating markets. Oxford, 2005.

SCHERMES, H. G.; BLOKKER, N. M. International institutional law, unity within diversity. $5^{\text {th }}$ ed. Leiden, 2011.

SEYERSTED, F. Common law of international organizations. Leiden-Boston, 2008.

SLAUGHTER, A.-M. A new world order. Princeton, 2004.

SYMPOSIUM on Perspectives on the Law of International Organizations as a Separate Field of Study. 5 International Organizations Law Review 141, 2008.

VEC, M. Recht und Normierung in der Industriellen Revolution: Neue Strukturen der Normsetzung in Völkerrecht, staatlicher Gesetzgebung und gesellschaftlicher Selbstnormierung. Frankfurt, 2006.

VIRALLY, M. Definition and classification: a legal approach. 29 Int. Soc. Sci. $58,1977$.

. La notion de fonction dans la théorie de l'organisation internationale. In: Mélanges offerts à Charles Rousseau: la communauté internationale. Paris, 1974. p. 277 e ss.

WEILER, J. H. H. The geology of international law - governance, democracy and legitimacy. 64 Zeitschrift für Ausländisches Recht und Völkerrecht 547, 2004.

WOLFRUM, R. International administrative unions. In: 2 Encyclopedia of public international law 1041 (first edition, R. Bernhardt (Ed.), 1995), and in the second edition (R. Wolfrum (Ed.)). 